\title{
Pediatric injuries in an Arabian Gulf country
}

\author{
Abdulbari Bener, Omer E F El-Rufaie, Naeema E K Al-Suweidi
}

\begin{abstract}
Objective-To determine the common types of injuries among children (0-14 years) in Al-Ain, United Arab Emirates (UAE).

Design-A retrospective descriptive hospital based study.
\end{abstract}

Setting-Al-Ain Medical District, Al-Ain Teaching Hospital, UAE.

Subjects-All patients aged 0-14 years seen at Al-Ain Teaching Hospital for injuries during 1994.

Results-The number of children with an injury who attended the emergency room was 16518 (69.9\% boys; 30.1\% girls). Injury rates were higher among nonUAE nationals. The most frequent reason for hospital admission was poisoning $(41 \%)$. In the age group $<5$ years, the most common causes were falls, blunt trauma, and burns or scalds, while in the 5-9 year and in 10-14 year groups the most frequent cause was road traffic accidents (RTAs). Fights and sporting injuries were also seen frequently in children aged 10-14 years.

Conclusion-Injury rates were higher in boys and RTAs mostly occurred in children over 10 years. The majority of cases (56\%) occurred among non-UAE nationals, who are usually of lower socioeconomic status.

Recommendation-Injuries can be prevented by developing strategies to substantially increase the profile of health education to parents and children, by educating policy makers and health professionals, and by environmental modification, legislation, and enforcement. The UAE government can play an important part by establishing and supporting injury prevention programs with these goals. (Injury Prevention 1997; 3: 224-226)

Keywords: United Arab Emirates.

Department of Pediatrics, Al-Ain Hospital, Ministry of Health, United Arab Emirates

NEK Al-Suweidi

Correspondence to: Dr Abdulbari Bener, Department of Community Medicine, Faculty of Medicine and Health Sciences, UAE University, PO Box 17666, Al-Ain, United Arab Emirates.

There has been tremendous growth in attention to injury as a public health problem. ${ }^{1}$ This growth is reflected in many ways, from the frequency of published articles in medical and public health journals to the scope of the Centers for Disease Control and Prevention's injury control efforts. ${ }^{2}$ Trauma is the leading cause of death among children aged 0-14 years in most countries through the world. are the leading cause of death in all induse tralized countries, ${ }^{3-9}$ including the oil produ cing countries, ${ }^{10}$ and a growing number of developing countries. ${ }^{9}$ Also, hospital admission rates due to injuries involving children ares increasing, ${ }^{11-14}$ although lengths of stay are diminishing. ${ }^{11-13}$ Admissions often account fow more than $30 \%$ of total admissions under the age of 2 years, and their effect on overafo admission rates is increasing. ${ }^{14} 15$

The aim of this study was to determine the common types of injury among children aged $0-14$ years in Al-Ain, United Arab Emirates (UAE).

Subjects and methods

The UAE lies on the Arabian Gulf with a coast line of about $650 \mathrm{~km}^{2}$. The UAE has undere taken three national population censuses. The most recent population was estimated af 2230000 in $1993 ; 32 \%$ are below 15 yearo of age. Expatriates comprise $70 \%$ of the tota population.

\section{STUDY DESIGN}

The study was descriptive and retrospective. If included all cases of child injuries treated at the emergency room at Al-Ain Teaching Hospitale in Al-Ain during 1994. Patients who die $\Phi$ before arrival were not included. Data col@ lected from emergency room records com prised two parts: (1) general: age, sex? nationality, data, arrival time, disposition, an (2) specific: type of injury, cause, and location.

The ages of patients were categorized as: $<5,5-9$, and $10-14$ years. Injuries were classified as contusions, cuts, lacerations? fractures, sprains, burns, scalds, poisonings bites, and others, including gun shot wounds
drowning, and foreign bodies.

One limitation of this study was the absence of information on specific components of socioeconomic status of parents that may be possible risk factors.

STATISTICAL METHODS From the age of 1 year to adulthood, injuries 
room. Most injuries were minor and did not require admission (95.6\%). Road traffic accidents (RTAs) had a higher incidence in the age group over 10 .

Table 1 presents the various characteristics of the cases. Seventy per cent of injuries were among males and most were between 10-14 years; $56 \%$ involved non-UAE nationals. This table also shows the most frequent causes of injury: superficial, falling, burns, and sharp objects.

Table 2 shows the different types of injury by sex, with a difference that is highly significant $(\mathrm{p}<0.0001)$. Boys are more frequently injured than girls for almost all injury types.

Table 3 gives the most common type of bites and their frequencies by sex. The most common bite was insect sting, followed by ant, and bee.

\section{Discussion}

In this study, most injuries were minor and did not require admission (95.6\%). Similar results

Table 1 Sociodemographic characteristics of subjects; values are frequency (\%)

\begin{tabular}{lll}
\hline & $\begin{array}{l}\text { Boys } \\
(n=11497)\end{array}$ & $\begin{array}{l}\text { Girls } \\
(n=5021)\end{array}$ \\
\hline $\begin{array}{l}\text { Age in years } \\
\quad<5\end{array}$ & $3744(32.6)$ & $2298(45.8)$ \\
$5-9$ & $3764(32.7)$ & $1661(33.1)$ \\
$\quad 10-14$ & $3989(34.7)$ & $1062(21.1)$ \\
Nationality & & \\
$\quad$ UAE & $5146(44.8)$ & $2118(42.2)$ \\
$\quad$ Non-UAE & $6351(55.2)$ & $2903(57.8)$ \\
Causes & & \\
Falling & $1614(14.0)$ & $845(16.8)$ \\
RTAs & $180(1.6)$ & $51(1.0)$ \\
Sharp object & $507(4.4)$ & $197(3.9)$ \\
Blunt object & $212(1.8)$ & $83(1.7)$ \\
Burns & $467(4.1)$ & $235(4.7)$ \\
Fight/sports & $164(1.5)$ & $41(0.8)$ \\
Superficial injuries & $8353(72.7)$ & $3569(71.1)$ \\
\hline
\end{tabular}

Table 2 Type of injuries by sex; values are frequency (\%)

\begin{tabular}{lll}
\hline Types of trauma & $\begin{array}{l}\text { Boys } \\
(n=11497)\end{array}$ & $\begin{array}{l}\text { Girls } \\
(n=5021)\end{array}$ \\
\hline No abnormality & $659(5.7)$ & $314(6.3)$ \\
Contusion & $4812(41.9)$ & $2130(42.2)$ \\
Cuts/lacerations & $3424(29.8)$ & $1425(28.4)$ \\
Fractures & $772(6.7)$ & $295(5.9)$ \\
Sprains & $383(3.3)$ & $135(2.7)$ \\
Burns/scalds & $482(4.2)$ & $241(1.9)$ \\
Poisoning & $105(1.0)$ & $77(1.5)$ \\
Bites & $293(2.5)$ & $134(2.7)$ \\
Nail prick & $255(2.2)$ & $95(1.9)$ \\
Others & $312(2.7)$ & $175(3.5)$ \\
\hline
\end{tabular}

^Others: including foreign bodies, gunshot, drowning.

Table 3 Types of bites by sex; values are frequency (\%)

\begin{tabular}{lll}
\hline Types of bite & $\begin{array}{l}\text { Boys } \\
(n=293)\end{array}$ & $\begin{array}{l}\text { Girls } \\
(n=134)\end{array}$ \\
\hline Insect & $97(33.2)$ & $49(36.7)$ \\
Ant & $72(24.5)$ & $31(23.2)$ \\
Bee & $38(13.0)$ & $13(9.4)$ \\
Scorpion/snake & $20(6.8)$ & $10(7.5)$ \\
Cat & $10(3.4)$ & $7(5.3)$ \\
Dog & $32(11.0)$ & $13(9.8)$ \\
Rabbit & $3(1.0)$ & $2(1.5)$ \\
Rat & $10(3.4)$ & $4(3.0)$ \\
Camel/sheep & $5(1.7)$ & $2(1.5)$ \\
Human & $6(2.0)$ & $3(2.2)$ \\
\hline
\end{tabular}

were obtained in the neighbouring country of Saudi Arabia. ${ }^{10} 12$ The majority of cases occurred in boys aged 10-14 years; most cases involving girls were $<5$ years old. The study confirms that boys predominate, as in many other studies. ${ }^{381012}$ This may be due to boys being more vigorous and adventurous than girls, who tend to be more confined to the home, especially in the Arab and Muslim culture.

As in most other studies, we found that falling was the most frequent cause of injury in children $<5$ years, while RTAs were more frequent in older children. This is in accord with findings from the USA $^{6}$ and Saudi Arabia. ${ }^{101216} \mathrm{~A}$ study in the neighbouring oil producing country of Saudi Arabia reported that falling was the most common cause of injury and an analysis of the mechanisms showed that most were preventable. ${ }^{101216}$

In children $<5$ years the home is the commonest place of injury. For example, oral exploration may lead to swallowing a variety of objects or liquids. Due to a large family size in the UAE community, older siblings may feed a newborn baby inappropriate foods. At any age, a bone hidden in food (for example fish) may be swallowed. Fractures and sprain were found more frequently in children above 10 years. Many prefer to go barefoot while playing, exposing themselves to nail prick injuries. This age group plays more football, cycles more, etc, and indulges in vigorous physical activities, especially boys. RTAs had a higher incidence in the age group over 10, a result obtained in other studies from the USA, ${ }^{6}{ }^{17}$ UK, ${ }^{14}$ Saudi Arabia, ${ }^{101218}$ and UAE. ${ }^{19}$ In the UAE, some boys use their parent's car without having a license.

The present study showed that the majority of cases (56\%) occurred among non-UAE nationals. Seventy per cent of the population are expatriates or non-UAE citizens. Also, it is noteworthy that non-UAE nationality may be a marker for poverty or lower socioeconomic status. Low socioeconomic status is a risk factor that is relatively well documented for injury. ${ }^{20}$ Recently a study showed that among the socioeconomic factors considered, low income was the single most important predictor of all injuries in northern Manhat$\tan .^{20}$

Most previous reports reveal the high cost of treating an injury. ${ }^{341619}$ Each year, one child in 10 suffers an injury for which it is necessary to call upon the health services at some level. ${ }^{3}{ }^{16} 19$ This is a significant expenditure for the UAE government. The primacy of health agencies is an essential ingredient in achieving better injury control. ${ }^{21}$ To ensure that the encouraging downward trends in mortality continue, injury control must be fully recognized as a public health problem. ${ }^{22}$ Injuries are amenable to prevention and their toll could be greatly reduced if appropriate measures are taken in the UAE. Official UAE data also confirm that injuries are the leading cause of mortality in children. ${ }^{19}$ Improvements in injury care in the $\mathrm{UAE}$ requires the creation and organization of regional injury centers, injury audits, and an injury registry. 


\section{Recommendation}

Most injuries can be prevented by developing strategies to substantially increase the profile of health education to parents and children, to educate policy makers and health professionals, and by environmental modification, legislation, and enforcement. The UAE government can play an important part by establishing and supporting an injury prevention program.

1 Waller JA. Reflections on a half century of injury control. $\mathrm{Am}$ F Public Health 1994; 84: 664-70.

2 Christoffel KK. Reducing violence-how do we proceed [editorial]. Am f Public Health 1994; 8: 539-41.

3 Manciaux M, Romer CJ. Accidents in childhood and adolescence: a priority problem worldwide. Geneva: World Health Organisation, 1991: 1-7.

4 Sola JE, Scherer LR. Criteria for safe cost effective pediatric trauma triage: pre-hospital evaluation and distribution of injured children. $\mathcal{F}$ Pediatr Surg 1994; 29: 738-41.

5 Stylianos S. Pediatric trauma prevention strategies. Pediatr Clin North Am 1993; 6: 1339-48.

6 Graneto JW, Soglin DF. Transport and stabilization of pediatric trauma patients. Pediatr Clin North Am 1993; 40: pediatric
$365-80$.

7 Moront M, Eichelberger MR. Pediatric trauma. Pediatr Ann 1994; 23: $186-91$

8 Christopher NC. Childhood injuries and the importance of documentation in the emergency department. Pediatr Emerg Care 1995; 11: $52-7$
9 Christophersen ER. Automobile accidents; potential years of life lost. Pediatrics 1983; 71: $855-6$.

10 Evbuomwan I. Pediatric trauma admissions in the Sakaka Central Hospital, Al-Jour Province, Saudi Arabia. Saudi Med f 1994; 15: 435-7. 11 Hill A. Trends in pediatric medical admission. BMF $1989 \overline{2}$.
298: $1479-82$.

$12 \mathrm{Al}-$ Salem AH, Qaisaruddin S. Trauma in a district generat hospital. Saudi Med f 1996; 18: 49-53.

13 Durojaye L, Hutchinson TP, Madeley RJ. Improved : primary care does not prevent the admission of childrer to hospital. Public Health 1989; 103: $181-8$.

14 Phalp A. Child accidents. Common, serious and prevenछ table. Practitioner 1994; 238: 766-9.

15 Spencer NJ, Lewis MA, Logan S. Diagnostic and socio demographic changes in multiple hospital admission in children under two years: a five-year period. $\mathcal{F}$ Publi children under two year:

16 Bener A, Jadaan KS. A perspective on road fatalities i\$ Jeddah, Saudi Arabia. Accid Anal Prev 1992; 24: 143-8.

17 Harris BH, Barlow BA, Ballantine TV. American Pediatri Surgical Association: principles of pediatric trauma care. f Pediatr Surg 1992; 27: 423-6.

18 Merdad A, Rawas M, Al-Garni $M$. Airgun injuries: gू national health hazard. Ann Saudi Med 1992; 12: 43-6.

19 Bener A, Breger A, Al-Falasi AS. Risk-taking behavior ī road traffic accidents. Fournal of Traffic Medicine 1994; 22 $\omega$ $67-70$.

20 Durkin MS, Davidson LL, Kuhn L, O'Connor P, Barlow B Low-income neighborhoods and the risk of severes pediatric injury: a small-area analysis in Northern pediatric injury: a small-area analysis in Northern

21 Macarthur C, Pless IB. Unintentional injury mortality in Canada. Pediatrics 1990; 80: $1073-7$.

22 Pless IB. Unintentional childhood injury-where the bucf should stop [editorial]. Am $\mathcal{F}$ Public Health 1994; 84: 537 过

\section{Call for ban on lethal child's toy}

A tiny child's toy was described as lethal by doctors yesterday after a 6 month old baby died and a 7 year old girl was left on a life support machine. The children accidentally swallowed the water bomb, a 2.5 " rubber balloon available for a few pence at scores of corner shops nationwide. They are intended to be filled with water then thrown.

Doctors at Bradford Royal Infirmary decided to speak out after dealing with two incidents in the past fortnight. In the first, on October 30, a 6 month old girl died after stuffing the balloon in her mouth at her home in Bradford. A verdict of accidental death was recorded at her inquest. Her father has called for the toy to be banned from sale.

In the second incident, last Sunday, the 7 year old girl inhaled the balloon after apparently trying to blow it up. She is critically ill in the hospital's intensive care unit.

The head of the accident and emergency department said: 'If these water bombs are accidentally inhaled, they are exactly then the right size to "sit" on a child's vocal chords and obstruct the windpipe. They have the shape, look, and texture of a miniballoon'.

West Yorkshire's Trading Standards Service has begun an investigation. Its head of fair trading and safety said the product was widely available. Packs of 20 sold for as little as $25 \mathrm{p}$. $\mathrm{He}$ declined to identify the water bomb importers as the inquiry had just been launched and, so far, only one importer had been traced (The Times, November 1996). 